\title{
Post preparation: cleanness achieved by different irrigating protocols
}

\author{
Marcela L. Roitman', Mariana Picca², Ricardo L. Macchi². \\ 1. Universidad de Buenos Aires, Facultad de Odontología, Cátedra de Endodoncia, Buenos Aires, Argentina. \\ 2. Universidad de Buenos Aires, Facultad de Odontología, Cátedra de Materiales Dentales, Buenos Aires, Argentina.
}

\begin{abstract}
The aim of this study was to evaluate the ability of different irrigation protocols to remove from the walls of the root canal and entrance to dentinal tubules the smear layer produced during preparation for a fiber post. Fifty decoronated human lower premolars were treated endodontically and the apical third of the canal was filled with a single gutta-percha point using warm vertical compaction. Ten millimeters were left free for post preparation, which was done by sequential use of a Largo \#1 drill and Exacto \#3 pilot drill (Angelus, Brazil), with irrigation with distilled water upon each instrument change. Samples were distributed randomly into 5 groups $(n=10)$. G 1: No irrigation after post preparation. $G$ 2: Distilled water activated for $60 s+$ distilled water. $\mathrm{G} 3: 5.25 \% \mathrm{NaOCl} 15 \mathrm{~s}+$ distilled water. G 4: 17\% EDTA (Farmadental, Argentina) $60 \mathrm{~s}+5.25 \% \mathrm{NaOCl}$ $15 s+$ distilled water. $G 5: 10 \%$ polyacrylic acid (Densell) 15 $s+$ distilled water. Irrigant was activated mechanically with a
\end{abstract}

low-speed conical brush. Roots were then split longitudinally in vestibular-lingual direction. Each surface was observed under SEM in its different thirds. Microphotographs were taken at $150 X$ and $600 X$ magnification and results analyzed statistically using Kruskall Wallis and Friedman tests $(p<0.05)$. The results [mean (standard deviation)] were: for 150X: G1 11.00 (1.33), G2 7.50 (3.13), G3 6.30 (2.58), G4 2.20 (2.80), G5 4.30 (1.50), and for $600 X \boldsymbol{G 1} 11.40$ (0.84), G2 10.00 (1.94), G3 7.70 (3.33), G4 5.80 (3.70), G5 7.20 (2.65). The statistical analysis showed significant differences between irrigants $(p<0.05)$ but not between root thirds $(p>0.05)$. The EDTA $+\mathrm{NaOCl}$ combination and polyacrylic acid showed greater capacity to remove the smear layer created during post preparation.

Received: March 2020; Accepted: July 2020.

Keywords: endodontics- smear layer- sodium hypochloriteedetic acid.

\section{Preparación para poste: limpieza lograda por diferentes protocolos de irrigación}

\begin{abstract}
RESUMEN
El objetivo del presente trabajo fue evaluar la capacidad de diferentes protocolos de irrigación para remover el barro dentinario de las paredes del conducto y entrada de los túbulos dentinarios, producido durante la preparación para anclaje intarradicular. Se utilizaron 50 premolares inferiores humanos a los cuales se les cortó la corona clínica. Luego se les realizó tratamiento endodóntico y obturación del tercio apical con cono único de conicidad aumentada y compactación vertical caliente. Se dejaron libres $10 \mathrm{~mm}$ para la preparación para poste que se realizó utilizando secuencialmente fresa de Largo \# 1 y fresa piloto Exacto \#1(Angelus, Brasil), irrigando a cada cambio de instrumento con agua destilada. Las muestras fueron distribuidas aleatoriamente en 5 grupos $(n=10)$. G 1: No se efectuó ningún lavaje. Los irrigantes fueron activados con cepillo mecánico cónico a baja velocidad. G 2: Agua destilada activada $60 \mathrm{~s}+$ agua destilada $\mathrm{G} 3$ : NaOCl al 5,25\%, $15 \mathrm{~s}+$ agua destilada. G 4: EDTA al 17\% (Farmadental, Argentina) $60 \mathrm{~s}$ $+\mathrm{NaOClal} 5,25 \% 15 \mathrm{~s},+$ agua destilada. G 5 : Ácido poliacrílico
\end{abstract}

al 10\% (Densell) $15 \mathrm{~s}+$ agua destilada. Posteriormente, las raices fueron seccionadas longitudinalmente en sentido vestíbulo lingual. Cada superficie fue observada al MEB en sus diferentes tercios. Las micrografías se realizaron a 150 y $600 \mathrm{X}$ y los resultados analizados estadísticamente mediante test de Kruskall Wallis y Friedman ( $<<0,05)$, Los resultados [Medias (desviaciones estándar)] fueron: para 150X G1 11,00(1,33), G2 7,50 (3,13), G3 6,30 (2,58), G4 2,20 (2,80), G5 4,30 $(1,50)$ y para $600 X \boldsymbol{G 1} 11,40(0,84), \boldsymbol{G} 210,00(1,94), \boldsymbol{G 3} 7,70$ (3,33), G4 5,80 (3,70), G5 7,20 (2,65). El análisis estadístico mostró diferencia significativa entre irrigantes $(p<0,05)$ pero no entre tercios radiculares $(p>0,05)$. La combinación de EDTA+NaOCl y el ácido poliacrílico tendrían mayor capacidad de remoción del barro dentinario creado durante la preparación para poste.

Palabras clave: endodoncia- barro dentinario, hipoclorito de sodio, EDTA. 


\section{INTRODUCTION}

Endodontically treated teeth usually have large carious lesions, crown fractures or overextended endodontic access that compromise retention of the restoration on the tooth remnant and therefore often require some form of anchoring for rehabilitation ${ }^{1}$. In the past, cast metal posts were used to connect the tooth remnant to the crown, but in recent years, fiberreinforced resin based posts have appeared on the market. One of the most usual complications with this type of adhesively cemented posts is that they become detached, crack or leak. The most frequent failure is due to detachment of the post, since the tooth-resin interface tends to be the weakest point in these adhesive attachments ${ }^{2-5}$.

Different adhesive systems and resin cements are currently used for bonding fiber posts, among which self-conditioning-resin cements have become popular. This system is less sensitive to operatory technique, reduces the number of clinical steps and the risk of procedural errors that exist when other bonding systems are used (moisture control, adequate solvent evaporation, among others). Nevertheless, because it is a polymeric cement, it involves the same requirements regarding absolute isolation of the operatory field - essential during the bonding of rigid structures, particularly root posts, where root canal asepsis is a priority. Its chemical formula includes multifunctional monomers with groups derived from phosphoric acid, which simultaneously demineralize and infiltrate enamel and dentin. Although the material mainly hardens due to a polymerization reaction typical of resins, it is also believed that it adheres chemically to the calcium of the hydroxyapatite in the dentin, a concept which is applied in another group of materials - the glass ionomers ${ }^{6}$.

The main disadvantage of self-conditioning resin cements is their low capacity to demineralize and infiltrate the thick smear layer remaining on the walls of the root canal after post preparation ${ }^{6,7}$.

The thickness of the smear layer in operative cavities is variable, ranging from $0.5 \mu \mathrm{m}$ to 5.5 $\mu \mathrm{m}$. It contains the same components as are present in dentin, such as collagen, glycosaminoglycans, denatured proteoglycans, hydroxyapatite, bacteria and minerals ${ }^{8}$. In post-endodontic dentin, it also contains odontoblastic processes and remains of endodontic filling material such as gutta-percha and endodontic sealer. The presence of the smear layer can hinder the dentin-resin association, while removing it may promote adhesion.

Different chemicals are used in endodontics and operative dentistry to remove the smear layer from the cavity walls completely or partially, including phosphoric acid, citric acid, polyacrylic acid, EDTA and sodium hypochlorite, among others. Although $37 \%$ phosphoric acid used prior to cementing with Relyx U 200 (3M ESPE) has been used successfully on enamel, where tensile strength increases considerably, it produces a harmful effect on bonding in dentin. This may be due to the fact that it is difficult for self-conditioning cement to infiltrate the layer of collagen fibers without the mineral support provided by acid etching ${ }^{9,10}$.

Action of $17 \%$ EDTA combined with sodium hypochlorite is based on EDTA chelating action on calcium ions, which produces gentle surface demineralization of dentin, while sodium hypochlorite acts subsequently, causing deproteinization of the collagen fibers denatured by the frictional heat in the area of burned or dehydrated dentin ${ }^{8}$. The use of sodium hypochlorite may have an adverse effect on bond strength, so it is controversial ${ }^{11}$.

Different concentrations of sodium hypochlorite alone are also used as irrigants. However, although sodium hypochlorite alone thins the smear layer, it does not completely remove it. The smear layer is only removed completely when sodium hypochlorite is used in combination with a chelating agent, as described above $\mathrm{e}^{11-13}$, since sodium hypochlorite does not dissolve inorganic matter.

Polyacrylic acid is used prior to the application of glass ionomer cements. It is a weak acid, commercially available at concentrations of $10 \%$ to $25 \%$ in water, with variations in $\mathrm{pH}$. At a concentration of $20 \%$, its $\mathrm{pH}$ is 1 , while at $10 \%$ it is 1.85 . This difference in $\mathrm{pH}$ may be associated to its ability to clean dentinal walls ${ }^{14}$. Treatment of root dentin with polyacrylic acid prior to use of Relyx U200 may remove the smear layer, open dentinal tubules, create some tags and increase bond strength $^{14,15}$.

The aim of this study was to contribute to the knowledge on the points described above by evaluating the ability of different irrigation protocols to remove from canal walls and dentinal tubule entrances the smear layer produced as a result of preparation for a root post. 


\section{MATERIALS AND METHODS}

This study was approved by the Ethics Committee of the Buenos Aires University School of Dentistry (code 001/2016).

This study used 50 human lower premolars, preserved in water at $37{ }^{\circ} \mathrm{C}$ until they were used, with average total length $21 \mathrm{~mm}$ to $23 \mathrm{~mm}$, without carious lesions, with fully developed apex, a single straight canal and patency to catheterization. Teeth with excessively oval anatomy were excluded (as determined by X-ray showing that the vestibularlingual:mesiodistal ratio in the middle third of the root canal was greater than 2:1).

In order to eliminate variables, clinical crowns were cut perpendicular to the long axis of the tooth, 2 $\mathrm{mm}$ above the proximal dentin-enamel junction, thus preserving a band of cervical dentin (ferrule effect). Then root catheterization was performed with a K\#10 file (Dentsply Maillefer, Ballaigues, Switzerland). Working length was determined with a k\#15 file at $1 \mathrm{~mm}$ before the apical foramen.

Root canals were prepared surgically using the ProTaper Universal mechanized instrumentation system (Dentsply Maillefer, Ballaigues, Switzerland), which consists of six nickel-titanium instruments with variable taper, according to the manufacturer's instructions. Specimens were instrumented using an electric motor with controlled torque at $300 \mathrm{rpm}$ (X Smart Plus, Dentsply Maillefer, Ballaigues, Switzerland), irrigation was performed after every change of instrument by applying $2 \mathrm{ml}$ of $2.5 \%$ sodium hypochlorite solution with Terumo 25G1 syringe and needle, up to a final instrument F3(30/09).

Final irrigation was performed with $17 \%$ EDTA (Farmadental, Buenos Aires, Argentina) for 1 minute, after which the root canal was dried with absorbent paper points, then rinsed with $2 \mathrm{ml}$ of $2.5 \%$ sodium hypochlorite solution for $30 \mathrm{~s}$. Both irrigant solutions were agitated with a sonic device with polymer tips (Endoactivator, Dentsply Tulsa, USA). Then the root canals were dried with absorbent paper points and the apical third filled with a F3 ProTaper gutta-percha point (Dentsply Maillefer, Ballaigues, Switzerland) followed by warm vertical compaction with Calamus Dual system (Dentsply, Maillefer). AH Plus (Dentsply, DeTrey, Germany) was used as endodontic sealer. This filling technique was used in order to keep free from endodontic material the walls of the cervical and middle thirds of root canal, where the space for the root post would be shaped. Post space was prepared at the same operatory time using \#1 Maillefer Largo drills (Dentsply Maillefer, Ballaigues, Switzerland) and \#1 calibrator drill white ring (\#70 apical diameter) from the kit (Exacto 1, Angelus, Brazil). Post space length was established at $10 \mathrm{~mm}$ from the cervical edge. During the procedure, irrigation was performed with distilled water to promote smear layer removal, lubricate and cool the root canal. Post space cleanness was evaluated using a stereomicroscope (Newton, Buenos Aires, Argentina) at 16X magnification. Specimens were divided randomly into 5 groups $(n=10)$ with different irrigation regimens (see below). All except the negative control group were irrigated using a Terumo 25 G1 syringe and needle (Terumo, Argentina) with rubber stopper placed 10 mm deep, with the needle moving gently in and out, allowing free backflow of irrigant solutions, and activated with a Rotoprox conical mechanical brush (HagerWerken, Germany) at low speed. Specimens were labelled according to the experimental groups listed below.

Group 1 (negative control): No irrigation after post preparation.

Group 2: Irrigation with distilled water $(3 \mathrm{ml})$ activated with Rotoprox for $60 \mathrm{~s}$ and final rinse with distilled water $(6 \mathrm{ml})$.

Group 3: Irrigation with $5.25 \%$ sodium hypochlorite solution ( $3 \mathrm{ml}$ ) activated with Rotoprox for $15 \mathrm{~s}$ and final rinse with distilled water $(6 \mathrm{ml})$.

Group 4: Irrigation with 17\% EDTA solution (Farmadental, Buenos Aires, Argentina) (3 ml) activated with Rotoprox for $60 \mathrm{~s}$, followed by $5.25 \%$ sodium hypochlorite solution $(3 \mathrm{ml})$ activated with Rotoprox for $15 \mathrm{~s}$ and final rinse with distilled water (3 ml).

Group 5: Irrigation with $10 \%$ polyacrylic acid solution (Densell) $(3 \mathrm{ml})$ activated with Rotoprox for $15 \mathrm{~s}$ and final rinse with distilled water $(6 \mathrm{ml})$.

Teflon and a thin layer of temporary filling material (Coltosol F, Coltene, Switzerland) were placed inside the canal to prevent entry of foreign particles and keep the samples immersed in water at $37^{\circ} \mathrm{C}$.

Two deep longitudinal grooves were shaped on the free faces using a constantly water-cooled lowspeed diamond disc, without reaching the root canal lumen. Then the teeth were split in half using an adhoc clamp. A fine-tip marker was used to mark the sides of each canal at $2 \mathrm{~mm}, 5 \mathrm{~mm}$ y $8 \mathrm{~mm}$, in order 
to enable identification of the points to be observed under scanning electron microscope.

The samples were dehydrated, mounted on an aluminum base, coated with a $20 \mathrm{~nm}$ gold-palladium layer and observed under scanning electron microscope (Zeiss, model Supra 40). Micrographs were taken at magnifications of $150 \mathrm{X}$ and $600 \mathrm{X}$ of the middle area of each third, at $2 \mathrm{~mm}$ (coronal third), $5 \mathrm{~mm}$ (middle third) and $8 \mathrm{~mm}$ (apical third) from the coronal reference.

The following numerical categories were used to evaluate cleanness of the root dentinal substrate:

Scale for cleanness (150X magnification)

0 : No smear layer.

1: Some particles with less than $20 \mu \mathrm{m}$ across.

2: A lot of smear layer.

Scale for dentinal tubules (600X magnification)

0 : All dentin tubules open with no visible smear layer.

1: Some dentinal tubules open and a thin smear layer covering tubule entrances.

2: All dentinal tubules covered.

The sum of the scores per category recorded for total observations performed on each experimental unit was taken as indicator for the situation of the variables (cleanness and tubules). Kruskall Wallis test was used for comparison among groups. For comparison of thirds within each group, the indicator considered was the sum of scores observed for each, and Friedman's test was applied. When required, tests for multiple comparisons were used. Significance was set as $\mathrm{p}<0.05$ for all cases.

\section{RESULTS}

Table 1 shows the results for the different groups, with arithmetic mean and standard deviation of the sum of scores for the variables cleanness and tubule exposure. Mean values for dentinal tubule opening were lowest (most open) in Group 4 (EDTA + sodium hypochlorite) and Group 5 (polyacrylic acid), though without significant difference compared to Group 3 (sodium hypochlorite). The 600x scanning electron microphotographs show that in Group 3 (sodium hypochlorite), the smear layer on dentin walls is thinner than in Group 2 (distilled water), although there is detritus plugging the lumen of dentin tubules. Group 4 (EDTA + sodium hypochlorite) and Group 5 (polyacrylic acid) are cleaner, with a higher number of open tubules (Fig. 1). Root walls were cleaner in Group 4 (EDTA + sodium hypochlorite) though not significantly different from Group 5 (polyacrylic acid). The 150X microphotographs show that brushing with water only (Group 2) was insufficient to clean the root dentin surface completely. Chemical solutions used as irrigants achieved greater cleanness (Fig. 2).

Practically no difference was observed for cleanness between root thirds, and when there was, the middle third was the cleanest (Table 2).

\section{DISCUSSION}

It is important to highlight that this study compared irrigation protocols, i.e., procedures to be performed by the operator before luting a root post with resin cement. These steps are relevant when using selfconditioning resin cements which do not require prior treatment of the dentinal substrate.

By definition, a procedure consists of following certain predefined steps in order to perform a task efficaciously. There may be different procedures for the same purpose, each of which will involve different steps and be more or less efficient.

The different activation times for the irrigants in each group are related to the specific intended chemical action on the smear layer, considering that brushing will exert mechanical action on it at the same time.

This study compares the effects of different irrigant solutions. From a clinical standpoint, it seeks to identify which solution achieves the cleanest possible dentin substrate in the shortest time and the simplest manner, with the aim of avoiding further complication of the maneuvers within the root canal. The procedures were selected based on the literature and were not standardized. Different irrigation protocols were found to provide different levels of cleanness and tubule opening.

\begin{tabular}{|c|c|c|}
\hline Group & Cleanness & Tubules \\
\hline I & $18.6(1.9) \mathrm{C}$ & $19.0(1.5) \mathrm{c}$ \\
\hline II & $12.1(5.0) b$ & $16.6(3.1) b, c$ \\
\hline III & $10.6(4.5) b$ & 12.6 (5.5) a,b \\
\hline IV & $3.3(4.2) a$ & $8.7(6.6) \mathrm{a}$ \\
\hline V & 6.8 (2.3) a,b & 11.7 (4.6) a,b \\
\hline
\end{tabular}

No statistically significant difference $(P>0.05)$ between values identified with the same letter within each variable. 


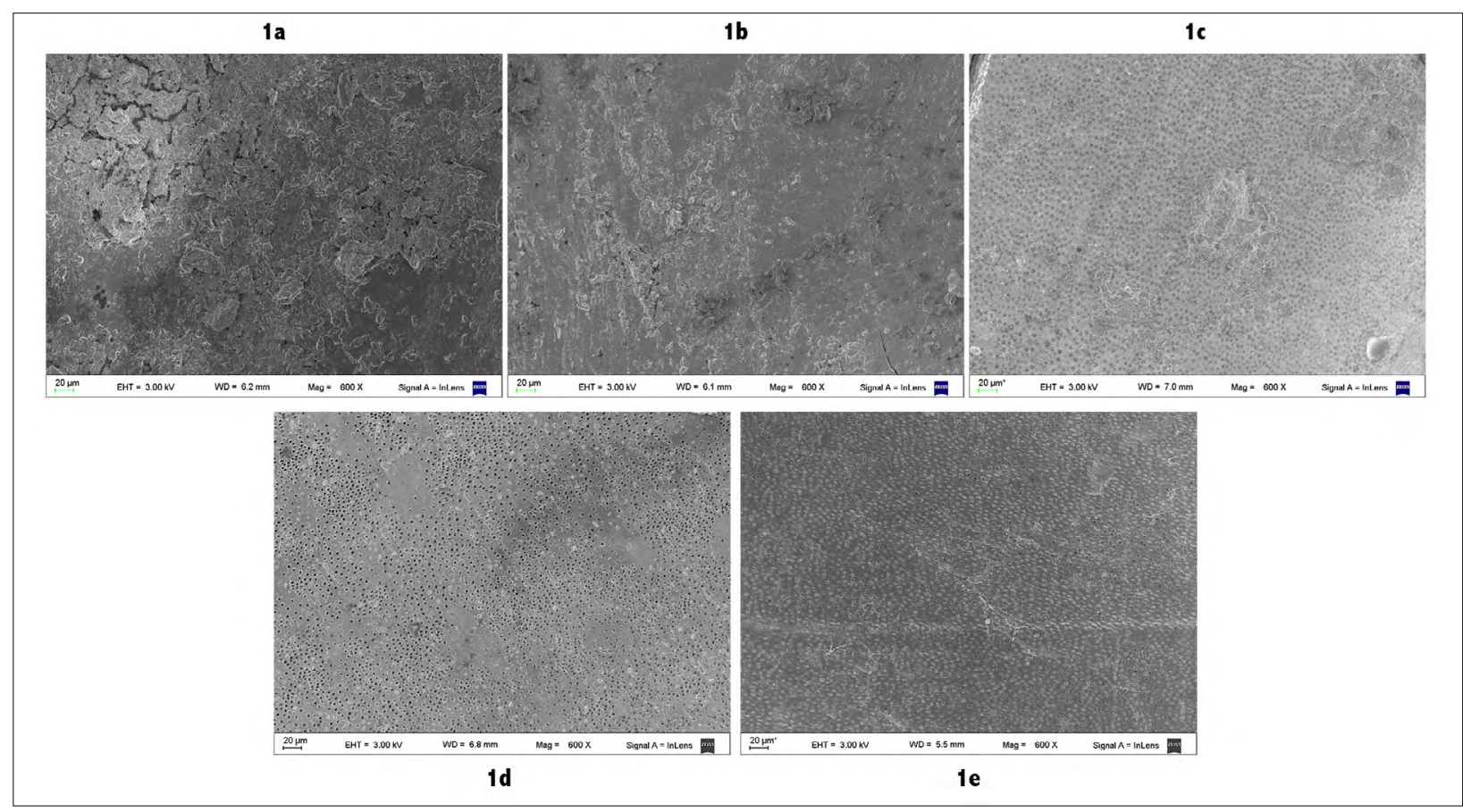

Fig.1. Scanning electron microphotographs of root middle third (600X) for observation of dentinal tubule openings.

la: Group 1, without irrigation. There is a dense, irregular smear layer completely covering the dentinal surface. 1b: Group 2, irrigation with distilled water activated with brushing. Persistent smear layer covering entrance to dentinal tubules. 1c: Group 3, irrigation with sodium hypochlorite. Noticeable thinning of smear layer, showing many dentinal tubules plugged with detritus. 1d: Group 4, irrigation with EDTA+ sodium hypochlorite. Many exposed dentinal tubules with opening free, without detritus on the surface. 1e: Group 5, irrigation with polyacrylic acid. Clean, many exposed dentinal tubules, though most of them are plugged.

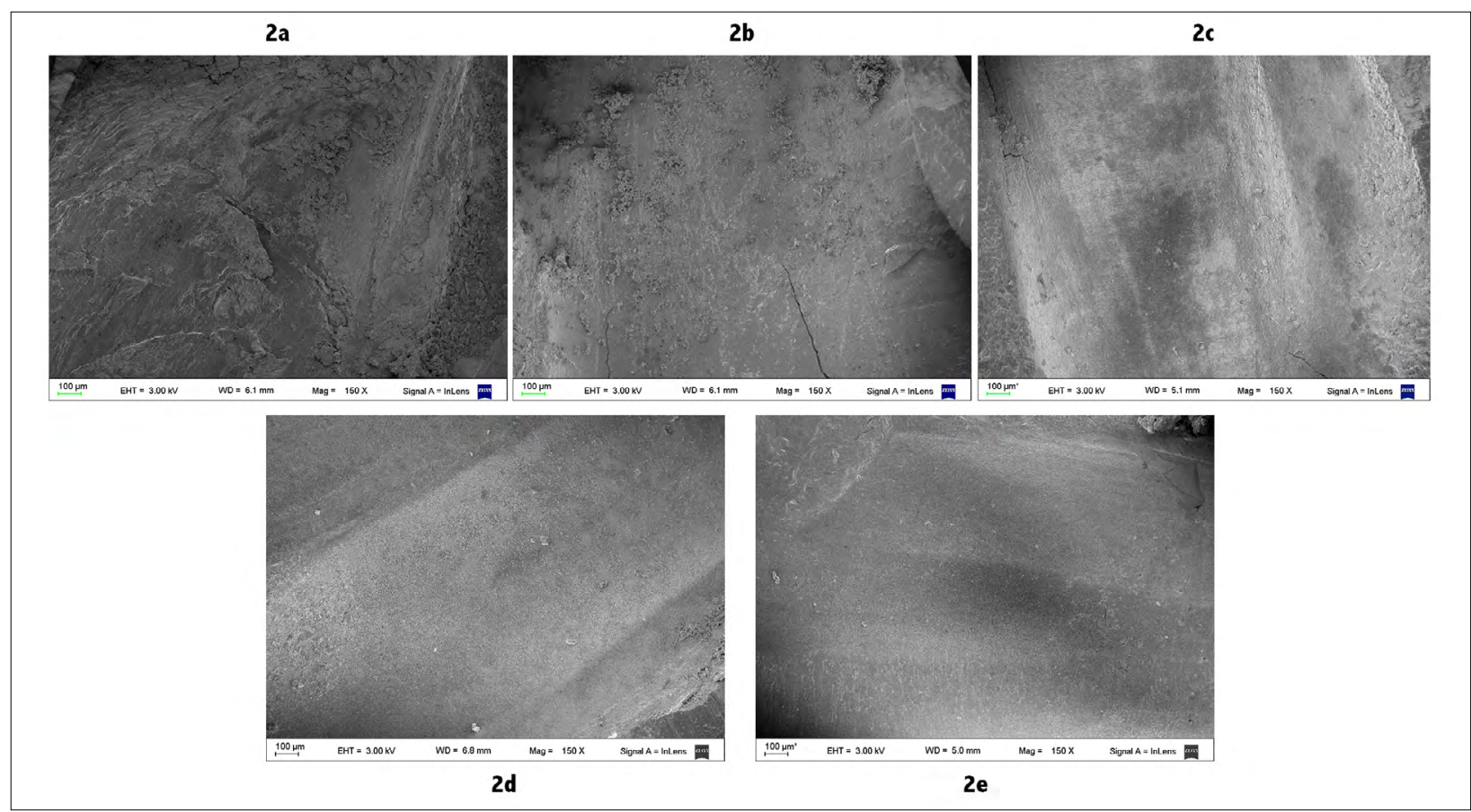

Fig. 2. Scanning electron microphotographs of the root middle third (150X) for observation of cleanness of root dentin surface. 2a: Group 1, without irrigation. There is a thick, dense, irregular smear layer with large detached particles greater than $100 \mu \mathrm{m}$ across. 2b: Group 2, irrigation with distilled water activated with brushing. There is a thinner smear layer, adhered to the surface, with smaller loose particles, less than 100 $\mu$ m across. 2c: Group 3, irrigation with sodium hypochlorite. There is a thinned smear layer without deposited particles. 2d: Group 4, irrigation with EDTA+ sodium hypochlorite. There is a clean dentinal surface, with few areas covered in detritus. 2e: Group 5, irrigation with polyacrylic acid. Cleanness similar to Group 4. 
Table 2. Comparison of cleanness and tubules between thirds within each experimental group.

\begin{tabular}{|c|c|c|c|c|c|c|}
\hline Group & \multicolumn{3}{|c|}{ Cleanness } & \multicolumn{3}{|c|}{ Tubules } \\
\hline I & Middle & Cervical & Apical & Middle & Cervical & $2.0 \mathrm{a}$ \\
\hline II & $1.2 \mathrm{a}$ & $2.6 \mathrm{~b}$ & $2.3 \mathrm{~b}$ & $2.0 \mathrm{a}$ & $2.1 \mathrm{a}$ & $2.2 \mathrm{a}$ \\
\hline III & $1.4 \mathrm{a}$ & $2.1 \mathrm{~b}$ & $2.6 \mathrm{~b}$ & $2.0 \mathrm{a}$ & $1.8 \mathrm{a}$ & $2.3 \mathrm{~b}$ \\
\hline IV & $1.3 \mathrm{a}$ & $2.4 \mathrm{~b}$ & $2.3 \mathrm{~b}$ & $1.4 \mathrm{a}$ & $2.3 \mathrm{~b}$ & $2.7 \mathrm{~b}$ \\
\hline V & $1.8 \mathrm{a}$ & $2.0 \mathrm{a}$ & $2.3 \mathrm{a}$ & $1.5 \mathrm{a}$ & $2.9 \mathrm{~b}$ & $2.3 \mathrm{a}$ \\
\hline
\end{tabular}

Values are means of the ordinal number for the third within each group and variable. Same letter within the third and the variable indicates non-significant difference $(P>0.05)$.

Irrigation with distilled water plus mechanical brushing was insufficient to clean the root dentin surface. Groups 4, 5 and 3 do not differ significantly from each other regarding the effect on dentin, though it should be noted that Group 4 tended to have better results. The lack of a noticeable statistical difference among groups may be due to the impossibility of homogenizing and evaluating the initial characteristics and cleanness of the root dentin. Some variables that are reflected by dentinal structure which are very difficult to control, such as tooth age, bruxism or other habits which may promote data dispersion.

In this ex vivo study, observations were made under scanning electron microscope at 150X and $600 \mathrm{X}$. The lower magnification $(150 \mathrm{X})$ provides a larger field of view, enabling a more general view for analyzing amount of smear layer and detritus, while the higher magnification (600X) enables identification of more sensitive situations such as removal of the smear layer on intertubular dentin and presence of plugs in dentinal tubule lumens.

A conical Rotoprox brush was used at low speed throughout the irrigant action period in an attempt to improve mechanical removal of the smear layer and detritus and to increase the contact between the irrigant and the dentin substrate. In a comparative study of cleaning preparation for root posts, Goldberg et al. reported that brushes soaked in alcohol did not improve the cleanness achieved with the original preparation ${ }^{16}$. The fillings-in said study were performed using hybrid technique (thermomechanical compaction), which probably hindered full removal of material stuck to canal walls.

Taking this into account, in the present study, post preparation was performed during the same endodontic treatment session by filling only the apical third and leaving the middle and coronal thirds free from endodontic material. When thirds were compared for cleanness, the middle third was found to be cleaner, possibly due to greater contact of the conical brush against the root canal walls.

Except for polyacrylic acid, the irrigants used in this study are commonly used in endodontic procedures. EDTA at $17 \%$ acts as a chelating agent of calcium ions, producing surface demineralization of dentin. Sodium hypochlorite at different concentrations causes deproteinization of exposed collagen fibers. This is probably why overall, Group 4 had the best results, in addition to being the irrigation protocol that used the Rotoprox brush for the longest time, perhaps achieving greater mechanical removal of the smear layer. This effect was also observed by $\mathrm{Wu}$ et al., who report that a smear layer of approximately $5 \mu \mathrm{m}$ generated by post preparation was practically dissolved after using EDTA and sodium hypochlorite as irrigants, with dentinal tubule orifices becoming visible ${ }^{17}$. Several authors have confirmed that the use of EDTA for long time causes mineral loss in intertubular and peritubular dentin, thereby reducing dentin hardness, so they recommend that exposure to this chelating agent should not exceed 5 minutes. Excessive exposure to EDTA may cause areas of eroded dentin, and this was also observed in some of the microphotographs in the present study. These results are in agreement with Ensinas et al. and other papers ${ }^{18,19}$.

In the present study, the smear layer was cleaned less in the group irrigated only with $5.25 \%$ sodium hypochlorite solution than when it was combined with EDTA, even though the layer was thinned, in agreement with $\mathrm{Gu}$ et al. In that study they report that the smear layer was mainly removed from the middle and coronal thirds of the preparation, although even so, dentinal tubules remained blocked with 
detritus ${ }^{20}$. Guerisoli et al. report that the action on the smear layer of a $1 \%$ sodium hypochlorite solution was similar to that of distilled water ${ }^{21 .}$ Baumgartner et al. report that $5.25 \%$ sodium hypochlorite in combination with ultrasonic agitation instead of rotary brushes did not effectively remove smear layer from root canal walls ${ }^{22}$.

It is worth noting that the manufacturer's instructions for Relyx U200 (3M) self-conditioning resin cement call for pre-treatment of root dentine by irrigation with sodium hypochlorite followed by rinsing with water. This recommendation may be related to the material's low affinity with the hydrated collagen fiber layer. When the organic components of the smear layer are removed, the mineral component increases and water content decreases. Relyx U200 contains functional phosphoric methacrylates that react with the calcium ions of the hydroxyapatite ${ }^{23}$. The current study used $5.25 \%$ sodium hypochlorite for $15 \mathrm{~s}$ because exposure times of $30 \mathrm{~s}$ or longer would affect resin cement polymerization ${ }^{24}$.

The third chemical compared in the present study was polyacrylic acid, which is used prior to applying

\section{ACKNOWLEDGMENT}

We thank Dr. Fernando Goldberg for reviewing the text and constant support.

\section{FUNDING}

This study was partly funded by Subsidy 20020160100037BA from the Scientific Programming Department of Buenos Aires University.

\section{REFERENCES}

1. Morgano SM. Restoration of pulpless teeth: application of traditional principles in present and future contexts. J Prosthet Dent 1996;75:375-380.

2. Purton DG,Love RM. Rigidity and retention of carbon fibre versus stainless Steel root canal posts. Int Endod J1996;29:262-265.

3. Parisi C, Valandro L F, Ciocca L, Gatto MR, Baldissara P. Clinical outcomes and success rates of quartz fiber post restorations: a retrospective study. J Prothet Dent 2015;114:367-372.

4. Boschian Pest L, Cavalli G, Bertani P, Gagliani M. Adhesive post endodontic restorations with fiber posts: push-out tests and SEM observations. Dent Mater 2002;18:596-602.

5. Sahafi A, Peutzfeldt A, Asmussen E, Gotfredsen K. Retention and failure morphology of prefabricated posts. Int J Prosthodont 2004;17:307-312.

6. Radovic I, Monticelli F, Goracci C, Vulicevic ZR, Ferrari M. Self adhesive resin cements: a literature review. J Adhes Dent 2008;10:251-258. glass ionomer cements in order to achieve greater interaction between the material and the dentin substrate $^{25}$.

In the current study, the action of $10 \%$ polyacrylic acid for $15 \mathrm{~s}$ proved to be sufficient to clean the dentin walls, with no significant difference compared to the EDTA/hypochlorite combination. Mazitelli et al. verified removal of the smear layer, opening of dentinal tubules and presence of some tags when dentin was pre-treated with polyacrylic acid prior to use of Relyx U200, and Stona et al..$^{15,14}$ found an increase in the bond strength of Relyx U200 and resin tag formation following pretreatment with $11 \%$ polyacrylic acid. These aspects were not evaluated in the present study.

\section{CONCLUSIONS}

Significant differences were found between irrigation protocols, though differences between root thirds were not very marked. Both the EDTA+ $\mathrm{NaOCl}$ combination and polyacrylic acid appear to have the greatest ability to remove the smear layer during post preparation.

\section{CORRESPONDENCE}

Dra. Marcela Laura Roitman

Montevideo $928 \mathrm{~Pb}$ "A" C1019ABT

CABA - Buenos Aires - Argentina

mlroitman@gmail.com

7. Ferracane JL, Stansbury J, Burke FJT. Self adhesive resin cements-chemistry, properties and clinical considerations. J Oral Rehabil 2011;38:295-314.

8. Gilberto Henostroza - Uribe Echeverría. Adhesión en Odontología restauradora. 2010. Ed Ripano. 2da. edición. Cap. 4. Pág. 110.

9. De Munck J, Vargas M, Van Landuyt K, Hikita K, Lambrechts P, Van Meerbeek B. Bonding of an autoadhesive luting material to enamel and dentin. Dent Mater 2004;20:963-971.

10. Hikita K, Van Meerbeek B, De Munck J, Ikeda T et al. Bonding effectiveness of adhesive luting agents to enamel and dentin. Dent Mater 2007;23:71-80

11. Gu X, Mao C, Liang C, Wang H, Kern M. Does endodontic post space irrigation affect smear layer removal and bonding effectiveness? Eur J Oral Sci 2009;117:597-603.

12. Wu H, Hayashi M, Okamura K, Koytchev E et al. Effects of light penetration and smear layer removal on adhesion of post-cores to root canal dentin by self-etching adhesives. Dent Mater 2009;25:1484-1492 
13. O'Connell M, Morgan L, Beeler W, Baumgartner. A comparative study of smear layer removal using different salts of EDTA. C. J Endod 2000;26:739-743.

14. Stona P, Borges G, Resende Montes M,Burnett Junior L, Blessman Weber J, Spohr A. Effect of polyacrylic acid on the interface and bond strength of self adhesive resin cements to dentin. J Adhes Dent 2013;15:221-227.

15. Mazzitelli C, Monticelli F, Toledano M, Ferrari M, Osorio R. Dentin treatment effects on the bonding performance of self-adhesive resin cements. Eur J Oral Sci 2010;118:80-86.

16. Goldberg F, Frajlich S, Balzano y coautoras. Estudio comparativo de la limpieza de las preparaciones para anclaje intrarradicular inmediatas y mediatas. Rev Asoc Odontol Argent 2004;92:36-39. URL: https://pesquisa.bvsalud.org/ portal/resource/es/lil-360186

17. Wu H, Hayashi M, Okamura K, Koytchev E et al. Effects of light penetration and smear layer removal on adhesion of post-cores to root canal dentin by self-etching adhesives. Dent Mater 2009;25:1484-1492

18. Ensinas P. Evaluación de los efectos del EDTA sobre el barro dentinario, en la dentina radicular, en distintos períodos de tiempo. Un estudio con microscopia electrónica de barrido. Rev Asoc Odontol Argent. 2010;98:73-77.

URL: https://pesquisa.bvsalud.org/portal/resource/es/lil-555214

19. Zmener O. Eficiencia de dos soluciones irrigantes, con y sin el complemento de un gel quelante, para la remoción del barro dentinario. Un estudio con microscopía electrónica de barrido. Rev Asoc Odontol Argent 2009 ;97:343-348. URL: https://pesquisa.bvsalud.org/portal/resource/es/lil-552793

20. Gu X, Mao C, Liang C, Wang H, Kern M. Does endodontic post space irrigation affect smear layer removal and bonding effectiveness? Eur J Oral Sci 2009;117:597-603.

21. Guerisoli D, Marchesan M, Walmsley A, Lumley P, Pecora J. Evaluation of smear layer removal by EDTAC and sodium hypochlorite with ultrasonic agitation. Int Endod J 2002;35:418-421.

22. O'Connell M, Morgan L, Beeler W, Baumgartner. A comparative study of smear layer removal using different salts of EDTA. C. J Endod 2000;26:739-743.

23. Kambara K, Nakajima M, Hosaka K, Takahashi M et al. Effect of smear layer treatment on dentin bond of selfadhesive cements. Dent Mater J 2012;31:980-987.

24. Prasansuttiporn T, Nakajima M, Kunawarote S, Foxton R, Tagami. J Effect of reducing agents on bond strength to NAOCl treated dentin. Dent Mater J 2011;27:229-234.

25. Inoue S, AbeY, Yoshida Y, De Munk J, Suzuki K, Lambretchts P, Van Meerbeek B. Effect of conditioner on bond strength of glass-ionomer adhesive to dentin/enamel with and without smear layer interposition. Oper Dent 2004;29:685-692. 